\title{
Using Gauss - Jordan elimination method with The Application of Android for Solving Linear Equations
}

\author{
Muhaimin Hasanudin ${ }^{1, a^{*}}$, Dedy Prasetya Kristiadi2,b, Khozin Yuliana ${ }^{1, c,}$, Rasyid Tarmizii,d, Dwina Kuswardani3,e, A Abdurrasyid ${ }^{3, f}$ \\ ${ }^{1}$ Information Systems Department, Raharja University,Jl. Sudirman, Banten,Indonesia \\ ${ }^{2}$ Computer Systems Department, Raharja University,Jl. Sudirman, Banten,Indonesia \\ 3Information Technology Department, Sekolah Tinggi Teknik - PLN, Jl. Duri Kosambi,Cengkareng, Jakarta, Indonesia \\ a muhaimin@raharja.info; b dedy.prasetya@raharja.info; ckhozin@raharja.info; d rasyid@raharja.info; e dwina250762@gmail.com; ${ }^{f}$ arasyid@sttpln.ac.id; \\ ${ }^{*}$ Corresponding Author \\ Whatsapp Number [+6285810630506]
}

How to Cite : Hasnudin, M., Kristiadi, D., P., Yuliana, K., Tarmizi, R., Kuswardani, D., Abdurrasyid, A. (2019). Using Gauss - Jordan elimination method with The Application of Android for Solving Linear Equations. International Journal for Educational and Vocational Studies, 1 (6), 609-613

\section{ARTICLE HISTORY}

Received:3 June 2019

Revised: 23 July 2019

Accepted: 20 September 2019

\section{KEYWORDS}

Linear equation

the Gauss-Jordan Elimination

Android Studio

\section{ABSTRACT}

Problems involving mathematical models appear in many scientific disciplines. Complex mathematical models sometimes cannot be solved by analytic methods using standard algebraic formulas. Computers play a major role in the development of the field of numerical methods because the calculation uses numerical methods in the form of arithmetic operations, the number of arithmetic operations is very large and repetitive, so manual calculations are often tedious and errors occur. This study aims to develop software solutions for linear equations by implementing the Gauss-Jordan elimination(GJ-elimination) method, building software for linear equations carried out through five stages, namely: (1) System Modeling (2) Simplification of Models, (3) Numerical Methods and algorithms, (4) programming languages using The Android Studio and (5) Simulation programs. Overall regarding content, proper software that can be used by students and lecturers in implementing numerical methods because there are ways to use the application and steps to solve linear equation problems using the GJ-elimination method

\section{INTRODUCTION}

Problems of Linear system of equations (LSE) is how to find a replacement value for the variables $\mathrm{x} 1, \mathrm{x} 2, \mathrm{x} 3 \ldots, \mathrm{xn}$ so that all these equations to be true, it attracted the attention of researchers and scientists for a long time because it is operating in a variety of applications in basic science(Ziad,2015). Scientific and technical problems can be solved by a system of linear equations(Atasoy,2012), many methods for solving linear systems such as direct and iterative methods(Michailidis,2011). In this study builds software solutions of linear equations with the GJ-elimination method based on Androids are expected to be used to solve mathematical problems so that it can be used by students, faculty and the public. The linear equation is a form of equations which together present a lot of variables(Atasoy,2012), as Figure 1 below:

$$
\begin{gathered}
a_{11} x_{1}+a_{12} x_{2}+a_{13} x_{3}+\ldots+a_{1 n} x_{n}=b_{1} \\
a_{21} x_{1}+a_{22} x_{2}+a_{23} x_{3}+\ldots+a_{2 n} x_{n}=b_{2} \\
a_{31} x_{1}+a_{32} x_{2}+a_{33} x_{3}+\ldots+a_{3 n} x_{n}=b_{3} \\
\ldots \quad \ldots \quad \ldots \quad \ldots \quad \ldots \quad \ldots \\
a_{n 1} x_{1}+a_{n 2} x_{2}+a_{n 3} x_{3}+\ldots+a_{n n} x_{n}=b_{n} \\
\left|\begin{array}{ccccc}
a 11 & a 12 & a 13 & \ldots & a 1 n \\
a 21 & a 22 & a 23 & \ldots & a 2 n \\
a 31 & a 32 & a 33 & \ldots & a 3 n \\
\ldots & \ldots & \ldots & \ldots & \ldots \\
a n 1 & \text { an2 } & \text { an3 } & \ldots & \text { ann }
\end{array}\right|\left|\begin{array}{c}
x 1 \\
x 2 \\
x 3 \\
\ldots \\
x n
\end{array}\right|=\left|\begin{array}{c}
b 1 \\
b 2 \\
b 3 \\
\ldots \\
b n
\end{array}\right|
\end{gathered}
$$

Figure 1. The system of Linear Equations.

A solution to of linear equations not only as lessons learned a method of numerical and explanation theoretical model mathematics by default or abstract, but also can be applied in the field of information technology specialists (Wang,2011). Android device is able to transfer the theory 
and calculation that bores into the data intuitive who helps a student can understand the method and the process of fast solution.

\section{METHODS}

\subsection{Augmented Matrix}

Augmented Matrix is a matrix that is an extension matrix A by adding a vector B in the last column (Akai, 1994; Bai, 2010) and written : Augmented (A) $=[\mathrm{A} \mathrm{B}$, as Figure 2 below.

$$
\left[\begin{array}{cccccc}
a 11 & a 12 & a 13 & \ldots & a 1 n & b 1 \\
a 21 & a 22 & a 23 & \ldots & a 2 n & b 2 \\
a 31 & a 32 & a 33 & \ldots & a 3 n & b 3 \\
\ldots & \ldots & \ldots & \ldots & \ldots & \ldots \\
a n 1 & \text { an2 } & \text { an3 } & \ldots & \text { ann } & b 4
\end{array}\right]
$$

Figure 2. Augmented Matrix

\subsection{Elementary Line Operations(ELO)}

Line Operations Elementary is one alternative in completing a matrix form such as determining the inverse matrix and applying a matrix to a system of linear equations using two methods namely Gauss Elimination and Gauss Jordan Elimination.

\subsection{The Gauss-Jordan elimination(GJ elimination)}

GJ-elimination is the development of the gauss elimination method (Akai,1994), except that the augmented matrix or identity matrix, on the left is converted into a diagonal matrix (Bai,2010; Ji,2010). Figure 3 below:

$$
\begin{gathered}
{\left[\begin{array}{cccccc}
a 11 & a 12 & a 13 & \ldots & a 1 n & b 1 \\
a 21 & a 22 & a 23 & \ldots & a 2 n & b 2 \\
a 31 & a 32 & a 33 & \ldots & a 3 n & b 3 \\
\ldots & \ldots & \ldots & \ldots & \ldots & \ldots \\
a n 1 & a n 2 & a n 3 & \ldots & \text { ann } & b n
\end{array}\right]} \\
{\left[\begin{array}{ccccccc}
1 & 0 & 0 & \ldots & 0 & d 1 \\
0 & 1 & 0 & \ldots & 0 & d 2 \\
0 & 0 & 1 & \ldots & 0 & d 3 \\
\ldots & \ldots & \ldots & \ldots & \ldots & \ldots \\
0 & 0 & 0 & \ldots & 1 & d n
\end{array}\right]}
\end{gathered}
$$

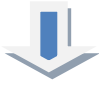

Figure 3. GJ-elimination

The process of the following a GJ- Elimination by changing the system of linear equations into a matrix augmentation and operating it. After becoming a partly reduced, matrix echelon line so directly can be determined the value of the variable is without the substitution of a back. Such as figure 4 below :

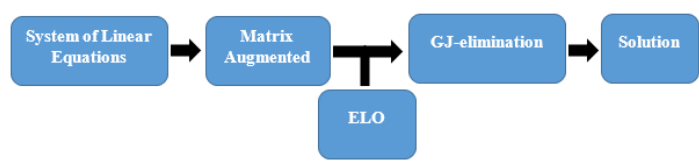

Figure 4. Procedure for GJ-elimination

\subsection{The Gauss Jordan Elimination Algorithm}

Solution to the problem of the system of linear equations known by using the method gauss-jordan (Michailidis, 2011). A GJ-elimination counting the opposite of a square matrix. By adding a matrix with the identity matrix of the dimensions of the same.The following an elimination algorithm gauss Jordan (Michailidis,2011; Moussa,2013).

1. Input matrix A and a Vector B and the order matrix / size $\mathrm{n}$

2. Make the Augmented matrix [A | B] name it with the A matrix

3. For lines to $\mathrm{i}=1$ to $\mathrm{n}$

a. Check value $\mathrm{A}_{\mathrm{i}, \mathrm{i}}=0$ :

b. If Yes :

Switch row $\mathrm{i}$ and row to $\mathrm{i}+\mathrm{k} \leq \mathrm{n}$, where $\mathrm{A}_{\mathrm{I}+\mathrm{k}, \mathrm{i}} \neq$ 0 , if it does not exist, the calculation can not continue and the process stops without completion

c. If No : continue

d. Make the diagonal value one, with the way for each column $\mathrm{k}$ where $\mathrm{k}=1$ up to $\mathrm{n}+1$, calculated $A_{i, k}=\frac{A i, k}{A i, i}$

4. For line $\mathrm{j}$, where $\mathrm{j}=\mathrm{i}+1=\mathrm{n}$

Do operation elementary line for a

column $\mathrm{k}$ where $\mathrm{k}=1=\mathrm{n}$

Count g c $=\mathrm{a}_{\mathrm{j}, \mathrm{i}}$

Count $\mathrm{A}_{\mathrm{j}, \mathrm{k}}=\mathrm{A}_{\mathrm{j}, \mathrm{k}}-\mathrm{C}^{*} \mathrm{~A}_{\mathrm{i}, \mathrm{k}}$

5. Do for $\mathrm{i}=\mathrm{n}$ to 1

$$
\mathrm{X}_{\mathrm{i}}=\mathrm{a} \mathrm{i}, \mathrm{n}+1
$$

Start

'Read the order of the matrix ' $n$ ' and read the coefficients of the linear equations

Do for $k=1$ to $n$

Do for $l=k+1$ to $n+1$

End for $l$ $a[k][l]=a[k][l] / a[k][k]$

Set $a[k][k]=1$

Do for $i=1$ to $n$

if ( $i$ not equal to $k$ ) then

Do for $j=k+1$ to $n+1$ End for $j$ $a[i][j]=a[i][j]-(a[k][j] * a[i][k])$

End for $i$

End for $k$

$$
\begin{aligned}
& \text { Do for } m=1 \text { to } n \\
& \quad x[m]=a[m][n+1] \\
& \text { Display } x[m]
\end{aligned}
$$

End for $m$

Stop

\section{RESULTS AND DISCUSSION}

In building software of linear equations done through five phases namely at the first and the second the job or scientist that is in accordance with its field by including the problems the equation linear and simplify model these 
problems if a required number. A third and fourth step is using a GJ-elimination method, in building the system using the Android Studio software and the last step with the simulation program for a test and evaluation such application.

The specifications of this software are the presence of a linear equation process with the GJ-elimination method. In this application, the user can enter the problem of linear equations and enter the number of Matrix Orders. The clean button functions to clean linear equation variables whiled the Jordan Gauss button functions to calculate the process of linear equations and display the results. In figure 5 below is the main display of software linear equations with GJ Elimination.

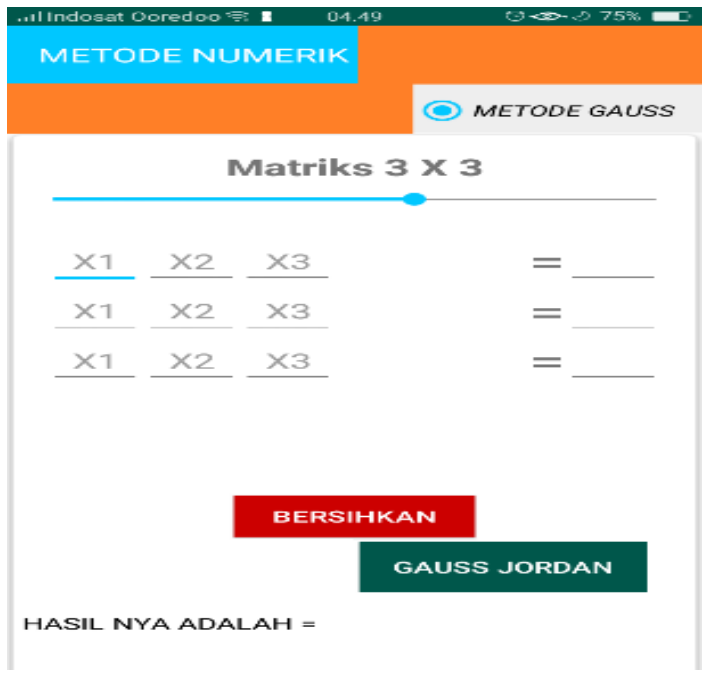

Figure 5. Main Display of Software GJ-elimination.

\subsection{Completion Simulation}

If the system is known the following linear equation:

$$
\begin{aligned}
& \mathrm{X}+\mathrm{Y}+2 \mathrm{Z}=9 \\
& 2 \mathrm{X}+4 \mathrm{Y}-3 \mathrm{Z}=1 \\
& 3 \mathrm{X}+6 \mathrm{Y}-5 \mathrm{Z}=0
\end{aligned}
$$

The first phase, make a matrix augmentation and linear, out of the equation change this matrix to matrix elimination (iteration) of the operations lined by doing some(Wijayaningrum,2017). Elementary As in the following The first phase, make matrix augmentation and of the equation linear above, change this matrix be matrix elimination (iteration) by doing some stage operation line elementary(Wijayaningrum,2017; Bains,1992). As below:

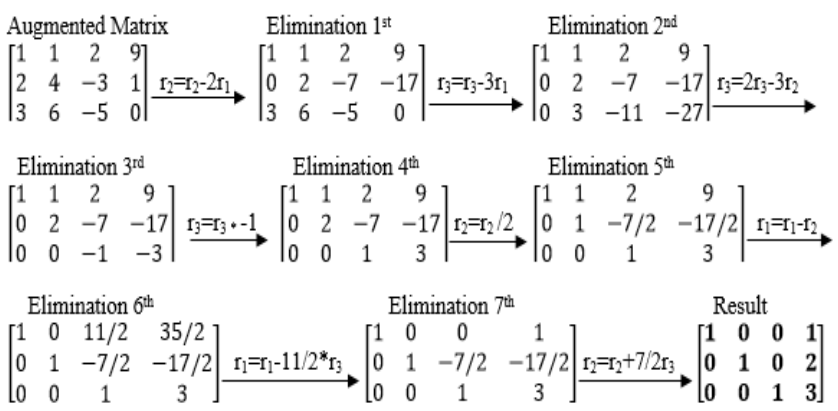

The explanation for the completion of a system of equations linear as follows :

1. Make a matrix augmentation of the equation linear above

2. Subtract the second row with $2 *$ the first row, stored in the second row $\rightarrow\left(\mathrm{r}_{2}=\mathrm{r}_{2}-2 \mathrm{r}_{1}\right)$

3. Subtract the third row with $3 *$ the first row, stored in the third row $\rightarrow(\mathrm{r} 3=\mathrm{r} 3-3 \mathrm{r} 1)$

4. The third row * 2 Subtract with $3 *$ the second row, stored in the third row $\rightarrow\left(\mathrm{r}_{3}=2 \mathrm{r}_{3}-3 \mathrm{r}_{2}\right)$

5. Multiply the third line with -1 , stored in the third row $\rightarrow(\mathrm{r} 3=\mathrm{r} 3 *-1)$

6. divided into 2 in the second row, stored in the second row $\rightarrow(\mathrm{r} 2=\mathrm{r} 2 / 2)$

7. Subtract the first row with the first row, stored in the first row $\rightarrow \quad\left(\mathrm{r}_{1}=\mathrm{r}_{1}-\mathrm{r}_{2}\right)$

8. Subtract the first row with $11 / 2$ * the third row, stored in the first row $\rightarrow \quad\left(r_{1}=r_{1}-11 / 2 * r_{3}\right)$

9. Add the second row with $7 / 2 *$ third row, stored in the second row $\rightarrow \quad\left(\mathrm{r}_{2}=\mathrm{r}_{2}+7 / 2 \mathrm{r}_{3}\right)$

10. Finished, the matrix has become an echelon matrix.

\subsection{Implementation}

As for the same settled with the gauss-jordan elimination :

$$
\begin{aligned}
& X+Y+2 Z=9 \\
& 2 X+4 Y-3 Z=1 \\
& 3 X+6 Y-5 Z=0
\end{aligned}
$$

The user determines the matrix order first, namely the $3 \times 3$ order matrix by dragging the line (the order of the matrix that is available is the $2 \times 2,3 \times 3,4 \times 4$ order matrix), then entering the parameters of the linear equation system and pressing the jordan gauss button. The application will display the problem solving and steps in linear equations in the smartphone screen. seen in figure 6 below this:

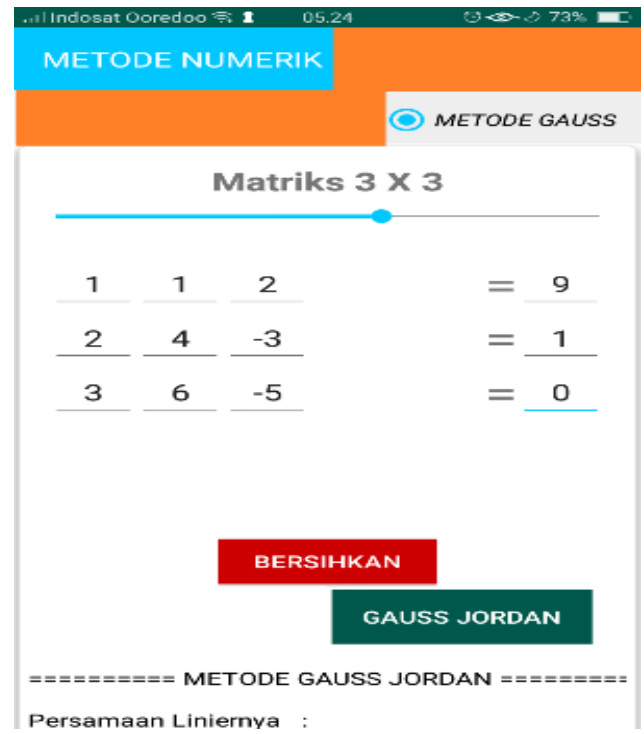

Figure 6. LSE Parameter Input and Order Matrix

So, the matrix : $\mathrm{X}=1, \mathrm{Y}=2$ dan $\mathrm{Z}=3$ 


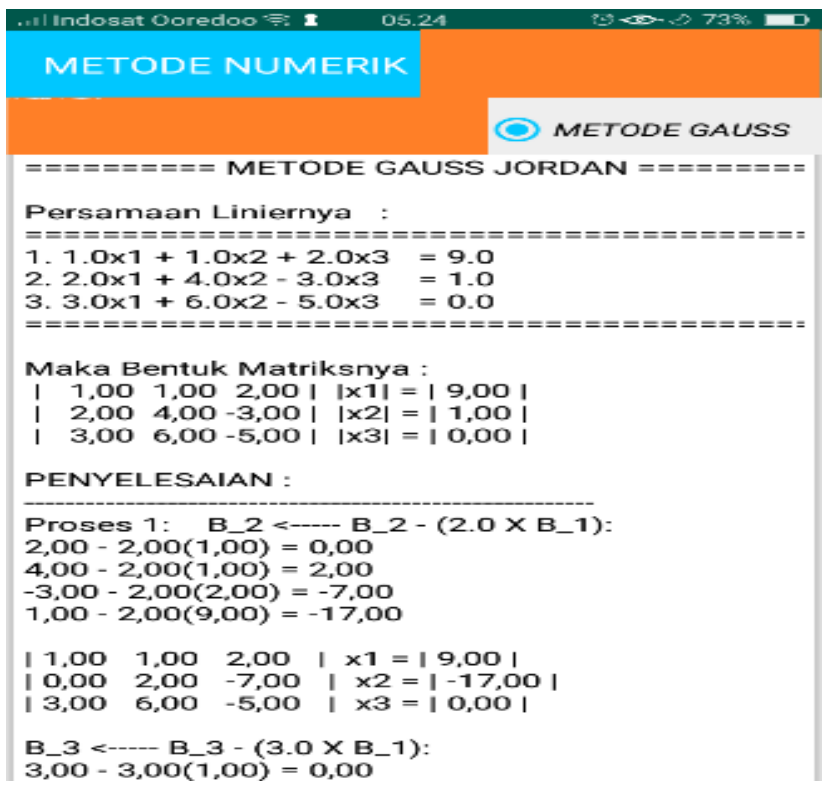

Figure 7. First discussion matrix

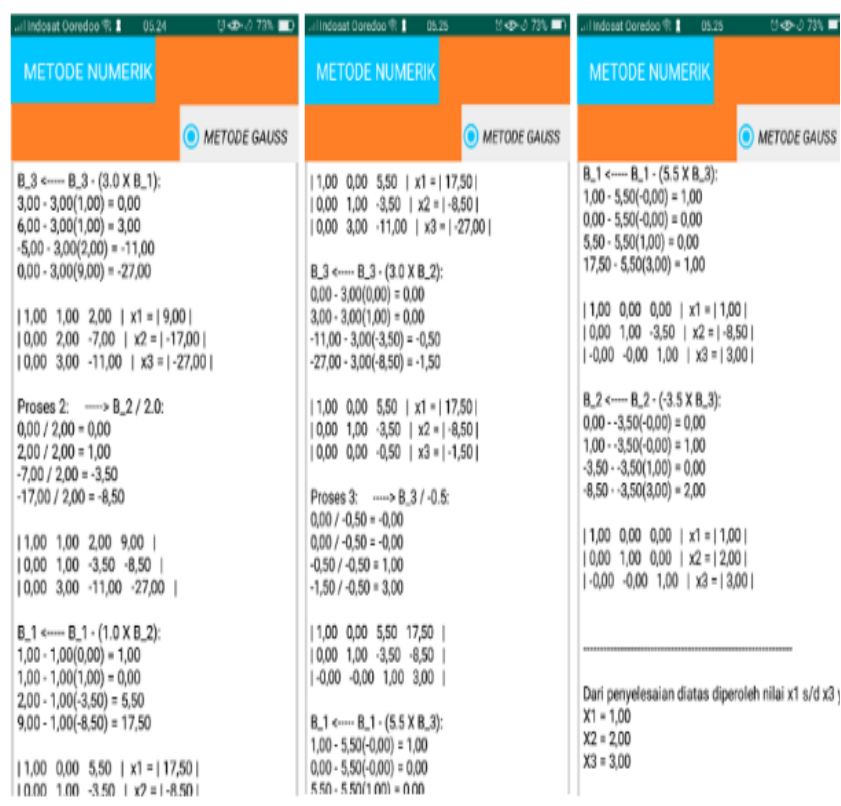

Figure 8. Matrix problem solving values of a variable $\mathrm{X}_{1} \cdot \mathrm{X}_{2}, \mathrm{X}_{3}$

\section{CONCLUSION}

The author has succeeded in making an application to complete a smartphone-based linear equation system using the GJ-elimination method. Based on the results of the experiment, this application is effective for solving linear equations and has been used by students and lecturers in solving linear equation system. Suggestions for the development of this application in the future is to make a graph of the results of solving linear equations and application development by directing the camera of the phone right on the question (scan) based on the frame provided, the system will detect and solve the problem.

\section{REFERENCES}

Ahmad, I. H., \& Ratnasari, L. (2010). Menyelesaikan Sistem Persamaan Linier Menggunakan Analisis SVD. Jurnal Matematika, 13(1), 40-45.

Anzt, H., Dongarra, J., Flegar, G., \& Quintana-Ortí, E. S. (2017, February). Batched gauss-jordan elimination for block-jacobi preconditioner generation on gpus. In Proceedings of the 8th International Workshop on Programming Models and Applications for Multicores and Manycores (pp. 1-10). ACM.

Atasoy. N.A, B. Sen, and B. Selcuk. (2012) "Using Gauss-Jordan elimination method with CUDA for linear circuit equation systems," Procedia Technol., vol. 1 , no. 1, pp. 31-35..

Akai. T. J.,(1994). "Applied Numerical Methods for Engineers," Eur. J. Eng. Educ., vol. 19, no. 4, pp. $515-516$.

Atasoy, N. A., Sen, B., \& Selcuk, B. (2012). Using gauss-Jordan elimination method with CUDA for linear circuit equation systems. Procedia Technology, 1, 31-35.

Bai. J, L. Gao, and L. He,(2010). "Constructing windows+gcc +mpi+omp and performance testing with Gauss-Jordan elimination method in finding the inverse of a matrix," 2010 Int. Conf. Comput. Des. Appl. ICCDA 2010, vol. 2, no. Iccda, pp. 2-5.

Bains R,(1992). "Elementary linear algebra," Eng. Anal. Bound. Elem., vol. 9, no. 4, p. 368.

Chapra, S. C., \& Canale, R. P. (2010). Numerical methods for engineers. Boston: McGraw-Hill Higher Education,.

Grcar, J. F. (2011). How ordinary elimination became Gaussian elimination. Historia Mathematica, 38(2), 163-218.

Guo, X., \& Gong, Z. (2010). Block Gaussian elimination methods for fuzzy matrix equations. International Journal of Pure and Applied Mathematics, 58(2), 157-168.

Isaacson, E., \& Keller, H. B. (2012). Analysis of numerical methods. Courier Corporation.

Ji, J. (2012). Gauss-Jordan elimination methods for the Moore-Penrose inverse of a matrix. Linear Algebra and Its Applications, 437(7), 1835-1844.

Ji, J., \& Chen, X. (2014). A new method for computing Moore-Penrose inverse through Gauss-Jordan elimination. Ap

Kharel, A., \& Cao, L. (2015, April). Decoding of short LT codes over BIAWGN channels with Gauss-Jordan elimination-assisted belief propagation method. In 2015 Wireless Telecommunications Symposium (WTS) (pp. 1-6). IEEE.

Kiusalaas, J. (2013). Numerical methods in engineering with Python 3. Cambridge university press.

Lu, L., Li, G. Y., Swindlehurst, A. L., Ashikhmin, A., \& Zhang, R. (2014). An overview of massive MIMO: Benefits and challenges. IEEE journal of selected topics in signal processing, 8(5), 742-758.

Moussa, S., Razik, A. M. A., Dahmane, A. O., \& Hamam, H. 
(2013). FPGA implementation of floating-point complex matrix inversion based on GAUSS-JORDAN elimination. In 2013 26th IEEE Canadian Conference on Electrical and Computer Engineering (CCECE) (pp. 1-4). IEEE.

Michailidis. P. D. and K. G. Margaritis. (2011). "Open multi processing (OpenMP) of Gauss-Jordan method for solving system of linear equations," Proc. - 11th IEEE Int. Conf. Comput. Inf. Technol. CIT 2011, pp. 314-319..

Nursuprianah, I., \& Sholikhah, M. (2009). Analisis kesulitan mahasiswa dalam memahami mata kuliah aljabar matriks (Studi kasus pada semester IV tadris matematika tahun akademik 2008/2009 di STAIN Cirebon). Jurnal EduMa, 1(1), 75-84.

Rosita, C. D., Laelasari, L., \& Noto, M. S. (2014). Analisis Kemampuan Pemahaman Matematis Mahasiswa pada Mata Kuliah Aljabar Linear 1. Euclid, 1(2).

Sasongko, S. B. (2010). Metode Numerik dengan Scilab. Penerbit Andi.

Simultan. P. L.,(2014). "Penyelesaian Persamaan Linier Simultan," pp. 31-44.

Sharma, G., Agarwala, A., \& Bhattacharya, B. (2013). A fast parallel Gauss Jordan algorithm for matrix inversion using CUDA. Computers \& Structures, 128, 31-37.

Stanimirović, P. S., \& Petković, M. D. (2013). Gauss-Jordan elimination method for computing outer inverses. Applied Mathematics and Computation, 219(9), 4667-4679.

Vijayalakshmi, V., \& Sattanathan, R. (2011). ST decomposition method for solving fully fuzzy linear systems using Gauss Jordan for trapezoidal fuzzy matrices. In International Mathematical Forum (Vol. 6, No. 45, pp. 2245-2254).

Wang. G, H. Liu, and X. Liu.(2011). "The application of excel in solving linear equations and nonlinear equation,” 2011 Int. Conf. Comput. Sci. Serv. Syst. CSSS 2011 - Proc., pp. 4081-4084.

Wijayaningrum V.N and F. Utaminingrum, (2017). "Numerical methods for initialization in fodder composition optimization," 2016 Int. Conf. Adv. Comput. Sci. Inf. Syst. ICACSIS 2016, pp. 397-400..

Yang, K., Li, Y., \& Xia, Y. (2013). A parallel method for matrix inversion based on gauss-jordan algorithm. Journal of Computational Information Systems, 9(14), 5561-5567.

Ziad. M.T.I, Y. Alkabani, and M. W. El-Kharashi.(2015) "On hardware solution of dense linear systems via Gauss-Jordan Elimination," IEEE Pacific RIM Conf. Commun. Comput. Signal Process. - Proc., vol. 2015-Novem, pp. 364-369. 